\title{
Resting EEG Activity and Ovarian Hormones as Predictors of Depressive Symptoms in Postmenopausal Women without a Diagnosis of Major Depression
}

\author{
Silvia Solís-Ortiz ${ }^{1}$, Elva Pérez-Luque ${ }^{1}$, Maria del Pilar Pacheco-Zavala ${ }^{2}$ \\ ${ }^{1}$ Departamento de Ciencias Médicas, División de Ciencias de la Salud, Campus León, \\ Universidad de Guanajuato, Guanajuato, México \\ ${ }^{2}$ Instituto de Mexicano del Seguro Social UMF53 de León, Guanajuato, México \\ Email: silviasolis17@prodigy.net.mx; elvaleticiaperez@yahoo.com; pilismolinski@yahoo.com
}

Received June $8^{\text {th }}, 2012$; revised July $17^{\text {th }}, 2012$; accepted August $16^{\text {th }}, 2012$

\begin{abstract}
The aim of this study was to examine the effects of depressive symptoms on resting EEG and their correlation with endogenous hormone levels in postmenopausal women without a diagnosis of major depresssion. Fifty postmenopausal women aged 48 to 60 years were assessed for depressive symptoms using the Beck Depression Inventory. EEG activity was recorded during rest with eyes closed in 23 participants with minimal and 27 with moderate depressive symptoms. Relative power for delta, theta, alpha1, alpha2, beta1 and beta 2 were analyzed and compared between women with minimal and moderate depressive symptoms. Hormonal levels of estrone, estradiol, progesterone, follicle-stimulating hormone and luteinizing hormone were obtained and correlated with the EEG parameters. The women with moderate depressive symptoms showed more relative alphalpower $(p=.01)$ and less relative beta 2 power $(p=.03)$. Relative theta and alpha2 power, estradiol levels and menopausal years were predictors of depressive symptoms. Progesterone was negatively correlated with the theta band $(p=.005)$ and positively correlated with the beta2 band $(p=.02)$ in women with moderate depressive symptoms. Estrone was negatively correlated with the alpha2 band $(p=.05)$, and estradiol was positively correlated with the theta band $(p=.02)$ and negatively correlated with the beta 2 band $(p=.05)$ in women with minimal depressive symptoms. These findings suggest that slow and fast EEG relative power, menopausal status and estrogen levels predict depressive symptoms and that progesterone is related with moderate depression.
\end{abstract}

Keywords: EEG; Estrogen; Progesterone; Depression; Postmenopause

\section{Introduction}

Many women experience depressive moods at the time of natural menopause and early postmenopausal periods (Harlow \& Abraham, 1999; Soares, 2010; Bromberger \& Kravitz, 2011). In some women these symptoms range from mild to severe and require treatment (Lebowitz, Pearson, \& Schneider, 1997; MacQueen \& Chokka, 2004; Dennerstein \& Soares, 2008), whereas in other women, symptoms are minor or absent, perhaps representing the common depressive symptoms of a typical woman in mid-life. Because depression coincides with the onset of natural menopause and early postmenopausal periods, it has been associated with ovarian hormones (Birkhauser, 2002; Studd \& Panay, 2004; Frey, Lord \& Soares, 2008; Ryan et al., 2009), particularly estrogens. The circulating level of estrogen in women shows a very steep decline over the 12 months after menopause, with elevated FSH (Meldrum, Davidson, Tataryn, \& Judd, 1981). Its decrease is associated with physiological changes affecting mood, mental state and memory (Fink, Sumner, Rosie, Grace \& Quinn, 1996). Several studies have reported that estrogens modulate serotonergic function and may exert effects on mood (Rubinow, Schmidt, \& Roca, 1998; Lasiuk \& Hegadoren, 2007; Soares \& Zitek, 2008). Thus, fluctuations in levels of estrogen have been correlated with emotional changes in mid-life women. However, the relationship between depressive symptoms and estrogen in menopause has not been clear. Most studies have examined depressive scores and their possible relation with sex hormones in menopausal or postmenopausal women diagnosed with major depression. In some cases, this approach has provided relevant information, but in other cases, the findings are discrepant. Some correlation studies of mood and hormone levels in menopause and postmenopause have found no association or weak associations (Birkhauser, 2002). Prospective studies have found the menopausal transition to be a period of heightened risk for the development of depressive symptoms or depression (Maartens, Knottnerus, \& Pop, 2002; Freeman et al., 2004; Woods et al., 2008; Soares, 2010). One prospective study did not find significant associations between depressive symptoms and absolute values of sex hormones in postmenopausal women, but the decline in estradiol was associated with increased risk of depressive symptoms (Ryan et al., 2009). These inconsistent results seem to be at least partly due to methodological problems and the fact that depressed mood cannot be equated with depressive disorder (Saletu et al., 1996; Smith, 1996; Vesco, Haney, Humphrey, Fu, \& Nelson, 2007). Therefore, the investigation of post-menopausal women without a diagnosis of major depression and a focus on objective measures of brain function and ovarian profile might provide additional information concerning the manifestation of depressive symptoms.

Electroencephalographic (EEG) methods in the resting state have been useful to assess brain function and depression be- 
cause EEG measurements differ between depressed individuals and normal subjects (Saletu, 1993; Kwon, Youn \& Jung, 1996; Debener et al., 2000; Morgan et al., 2005; Herrington et al., 2010). In patients with major depression have found increased slow wave activity (Adler, Bramesfeld, \& Jajcevic, 1999), increased alpha and beta activity (Pollock \& Schneider 1990), more delta power (Morgan et al., 2005), increased delta, theta and beta activity and decreased alpha activity (Begić et al., 2011) and frontal asymmetry (Debener et al., 2000; Deslandes et al., 2008). The EEG approach has also been applied to evaluate menopausal women with major depression, although few studies are reported in the literature. The EEG maps of menopausal women with a diagnosis of major depression show less total power and absolute power in the delta, theta and beta band, more relative delta and less alpha power than controls and significant relationships between estradiol levels and EEG measures (Saletu et al., 1996; Saletu, Anderer, \& Saletu-Zyhlarz, 2010). However, depressive symptoms in postmenopausal women without a diagnosis of major depression and their relation to ovarian profile and EEG measures are not well understood. The aim of the current study was to examine the effects of depressive symptoms in postmenopausal women without major depression on resting EEG measures and their relationship to hormone levels of estradiol, estrone, FSH, LH and progesterone. It was hypothesized that resting EEG would differ depending on the intensity of depressive symptoms and would be related to the hormonal profile. This approach will help to better understand postmenopausal depression and to implement strategies of prevention and treatment in future research.

\section{Method}

\section{Participants}

A total of 136 women responded to recruitment advertisements in a cross-sectional study. All respondents met the DSM-IV (American Psychiatric Association, 2000) criteria for a diagnosis of mood disorder or psychosis and ruled out major depression. Of the 136 respondents, 50 postmenopausal women volunteers between 48 and 60 years old with an intact uterus met the criterion of no history of major depression and were assessed for depressive symptoms. This sample size was calculated to yield an expected statistical power of .99 to detect a $10 \%$ difference in minimal and moderate depressive symptoms with a two-sided significance level of $\alpha=.05$. All women were given a medical history interview to assess their health status. To participate in the study, the women must have been amenorrheic for at least 12 months and had no history of cardiovascular, head trauma, brain surgery, stroke, or metabolic, endocrinological or malignant diseases. None of the participants were taking any type of medication at the time of the study or had ever received hormonal treatment. Participants were tested in a single session by one trained female (between $0900 \mathrm{~h}$ and 1100 h). Participants were instructed to abstain from caffeine, alcohol and smoking and to sleep for $8 \mathrm{~h}$ on the day prior to testing. This study was approved by the Ethics Committee of the Department of Medical Sciences of the University of Guanajuato for Research on Human Subjects, and is in accordance with the Declaration of Helsinki. All subjects provided written informed consent prior to participating in the study.

\section{Mood Questionnaire}

Depressive symptoms were evaluated through self-report us- ing the Beck Depression Inventory (BDI) (Beck \& Steer, 1993) in a standardized version for the Mexican population (Jurado et al., 1998) in the 50 women included in the study. This questionnaire consists of 21 items that measure current depressive symptoms. Each item contains a group of four statements, from which the subject chooses one according to how she felt in the last week. Individual questions of the BDI assess mood, pessimism, sense of failure, self-dissatisfaction, guilt, punishment, self-dislike, self-accusation, suicidal ideas, crying, irritability, social withdrawal, body image, work difficulties, insomnia, fatigue, appetite, weight loss, bodily preoccupation, and loss of libido. Items 1 to 13 assess symptoms that are psychological in nature, while items 14 to 21 assess more physical symptoms. The BDI has a reliability high (Cronbach's alpha coefficient of .85), meaning that the items on the inventory are highly correlated with each other. The BDI has concurrent validity in that it tends to agree with other measures of depression (correlations of .93 and .84). The total score is obtained by adding the scores for the 21 items, with 0 as the lowest score and 64 as the maximum score. Depressive scores were compared between groups with minimal and moderate depressive symptoms.

\section{EEG Recording}

EEG activity was recorded between $0900 \mathrm{~h}$ and $1100 \mathrm{~h}$ during rest with eyes closed. Twenty-two electrodes were placed according to the 10 - 20 International System at F3, F4, F7, F8, FC3, FC4, C3, C4, CP3, CP4, P3, P4, O1, O2, FT7, FT8, Fz, $\mathrm{FCz}, \mathrm{Cz}, \mathrm{CPz}, \mathrm{Pz}$ and $\mathrm{Oz}$ using a Quick Cap (model Neuroscan). The ipsilateral earlobes were used as a reference for electrode placement. EEGs were recorded on a 40-channel NuAmps model digital amplifier (Neuroscan) set to pass frequencies from .5 to $35 \mathrm{~Hz}$. EEG activity was recorded on a personal computer at a sampling rate of $512 \mathrm{~Hz}$ and was analyzed off line. EEG activity was carefully inspected for eye movement artifacts. Epochs with artifacts or signs of sleep were discarded from the analyses. During recordings, participants were instructed to relax comfortably in a chair and to place their chin on an individually adjusted head-rest. This recording session consisted of a 5 min period with eyes closed. A minimum of 20 long artifact free epochs, each 2 seconds in length (John \& Prichep, 1980) were selected for further processing to obtain the global relative power values for the following bands: delta, $.5-4.0 \mathrm{~Hz}$; theta, $4.0-8.0 \mathrm{~Hz}$; alpha1, $8.0-11.0 \mathrm{~Hz}$; alpha2, 11.0 - $14.0 \mathrm{~Hz}$; beta1, 14.0 - $25.0 \mathrm{~Hz}$; and beta2, 25.0 $35.0 \mathrm{~Hz}$. The relative power values of each frequency band were compared between groups with minimal and moderate depressive symptoms.

\section{Hormonal Measurements}

A $10 \mathrm{~mL}$ blood sample was collected from participants. ELISA was used to determine the $17 \beta$-estradiol and progesterone levels. Commercially available radioimmunoassay kits were used to determine follicle-stimulating hormone (FSH), and luteinizing hormone $(\mathrm{LH})$ levels. The serum hormone levels were used to confirm the hormonal status of participants and to establish relations with EEG variables.

\section{Statistical Analysis}

Statistical analyses were performed with STATISTICA for Windows 8 (StatSoft, Inc). Before statistical procedures were applied, the data were tested for normal distribution using 
Levene's test. Student's t-test was used to compare the demographic characteristics of the participants their depressive symptoms scores. A Mann-Whitney U test was used to compare the hormonal levels among participants with minimal and moderate depressive symptoms. Student's t-test was also used to compare EEG variables of global relative power among participants with minimal and moderate depressive symptoms. The Spearman correlation test was used to correlate the variables of EEG relative power to hormone levels and depressive symptom scores. Hormonal variables were transformed to logarithms to fit the normal distribution and to apply multivariate analysis. A multiple regression analysis was used to assess the relative contribution of depressive symptoms as an independent variable, with demographic variables, hormone levels and EEG relative power as independent variables. The Visual Statistics System (ViSta) for Windows 7.9 module "Effect size" was used to correct the data outlier and estimate the effect sizes. Effect sizes are indicated by the coefficient $\left(\rho_{I}\right)$ between minimal and moderate depressive symptoms groups. The $\rho_{I}$ values were squared to ease interpretation in terms of the percentage of the total variance associated with an effect. Significance was defined as alpha levels of $p<.05$.

\section{Results}

\section{Depressive Symptoms}

Of the fifty participants included in the study, 23 scored between 0 and 9 on the Beck Depression Inventory and were considered the group with minimal depressive symptoms. In the remaining group, 27 scored between 10 and 35 and were considered the group with moderate depressive symptoms. The comparison of depressive symptoms between these two groups was significant $\left(\mathrm{t}=10.238, p=.0000001, \rho_{I}=.85\right.$, explaining $73.10 \%$ of the total variance in the data) (Figure 1). The participants did not show scores of severe depressive symptoms.

\section{Characteristics of Participants}

The women with minimal and moderate depressive symptoms did not differ significantly in age, schooling, menarche, menopausal years, blood pressure, weight, height, body mass, pregnancies, glucose, alcoholism and smoking (Table 1). The women with minimal and moderate depressive symptoms did not differ significantly in hormonal levels of FSH, LH, 17ß-estradiol, and

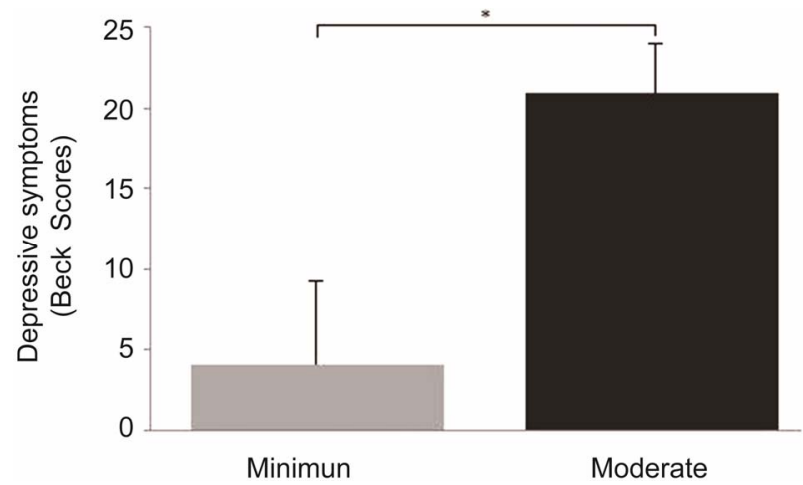

Figure 1.

Shows minimal and moderate depressive scores obtained from the Beck Depression Inventory. Asterisk on the bars indicate significant differences between groups $\left({ }^{*} p<.05\right)$. progesterone. The hormonal profiles were within the expected ranges for postmenopausal healthy women (Table 2).

\section{Correlations between Depressive Symptoms and Hormones}

Table 3 shows the results of a Spearman rank correlations analysis between depressive symptoms and hormone levels. The correlation analysis showed that minimal depressive symptoms did not correlate significantly with $\mathrm{FSH}, \mathrm{LH}$, progesterone, estrone and estradiol levels. Only moderate depresssive symptoms were negatively correlated with estradiol $(\mathrm{r}=-.66, p<.05)$.

Table 1.

Demographic characteristics of postmenopausal women with minimal and moderate depressive symptoms.

\begin{tabular}{|c|c|c|c|c|}
\hline \multirow{3}{*}{ Characteristics } & \multicolumn{4}{|c|}{ Minimal Depressive Moderate Depressive } \\
\hline & $\begin{array}{c}\text { Symptoms } \\
(\mathrm{n}=23)\end{array}$ & $\begin{array}{c}\text { Symptoms } \\
(\mathrm{n}=27)\end{array}$ & \multirow[t]{2}{*}{$\mathrm{t}$} & \multirow[t]{2}{*}{$p$} \\
\hline & Mean \pm SD & Mean \pm SD & & \\
\hline Age (years) & $54 \pm 4.0$ & $51 \pm 3.0$ & .889 & .11 \\
\hline $\begin{array}{l}\text { Menarche } \\
\text { (years) }\end{array}$ & $12 \pm 1.0$ & $13 \pm 1.0$ & .958 & .35 \\
\hline Menopause (years) & $48 \pm 3.9$ & $46 \pm 4.0$ & -1.244 & .22 \\
\hline Gestation (n) & $3.0 \pm 2.0$ & $5.0 \pm 3.0$ & 1.761 & .11 \\
\hline Weight (Kg) & $72 \pm 13$ & $68 \pm 7.0$ & -.426 & .10 \\
\hline Size (m) & $1.5 \pm .10$ & $1.5 \pm .10$ & -.905 & .90 \\
\hline BMI $\left(\mathrm{Kg} / \mathrm{m}^{2}\right)$ & $30 \pm 5.0$ & $30 \pm 3.0$ & .111 & .91 \\
\hline SBP (mmHg) & $113 \pm 11$ & $107 \pm 9.0$ & .335 & .40 \\
\hline DBP (mmHg) & $69 \pm 6.0$ & $65 \pm 5.0$ & .533 & .06 \\
\hline Glucose (mg/dL) & $87 \pm 12$ & $65 \pm 5.0$ & .860 & .06 \\
\hline
\end{tabular}

Note: $p$ values $<.05$ Student's t test; BMI $=$ Body Mass Index; SBP $=$ Systolic Blood Pressure; DBP = Diastolic Blood Pressure.

Table 2.

Serum hormone levels in postmenopausal women with minimal and moderate depressive symptoms.

\begin{tabular}{lcccc}
\hline \multirow{2}{*}{ Hormones } & $\begin{array}{c}\text { Minimal Depres- } \\
\text { sive Symptoms } \\
(\mathrm{n}=23)\end{array}$ & $\begin{array}{c}\text { Moderate Depres- } \\
\text { sive Symptoms } \\
(\mathrm{n}=27)\end{array}$ & $\mathrm{z}$ & $\mathrm{p}$ \\
\cline { 2 - 4 } & Median (range) & Median (range) & & \\
\hline FSH $(\mathrm{mUI} / \mathrm{mL})$ & $31.0(13.3-37.1)$ & $28.0(22.1-39.8)$ & -.37 & .70 \\
LH $(\mathrm{mUi} / \mathrm{mL})$ & $44.4(33.2-59.5)$ & $51.9(39.7-56.4)$ & -.45 & .65 \\
Progesterone $(\mathrm{ng} / \mathrm{mL})$ & $.2(.10-.6)$ & $.40(.1-1.0)$ & -.80 & .42 \\
Estrone $(\mathrm{pg} / \mathrm{mL})$ & $8.2(1.2-24.2)$ & $23.8(1.2-39.9)$ & -.68 & .49 \\
Estradiol $(\mathrm{pg} / \mathrm{mL})$ & $11.9(2.6-22.9)$ & $10.1(2.9-16.8)$ & .38 & .71 \\
\hline
\end{tabular}

Note: $\mathrm{FSH}=$ Follicle Stimulating Hormone; $\mathrm{LH}=$ Luteinizing Hormone; $\mathrm{p}$ values $<.05$ Mann-Whitney U test.

Table 3.

Correlation between minimal and moderate depressive symptoms and serum hormone levels.

\begin{tabular}{lcc}
\hline Hormones & $\begin{array}{c}\text { Minimal Depressive } \\
\text { Symptoms }\end{array}$ & $\begin{array}{c}\text { Moderate Depressive } \\
\text { Symptoms }\end{array}$ \\
\hline FSH $(\mathrm{mUI} / \mathrm{mL})$ & .29 & .08 \\
LH $(\mathrm{mUI} / \mathrm{mL})$ & .37 & -.12 \\
Progesterone & -.51 & -.17 \\
$(\mathrm{ng} / \mathrm{mL})$ & -.11 & -.20 \\
Estrone $(\mathrm{pg} / \mathrm{mL})$ & -.21 & $-.66^{*}$ \\
Estradiol $(\mathrm{pg} / \mathrm{mL})$ &
\end{tabular}

Note: ${ }^{*} p<.05$ Spearman Correlation test; FSH = Follicle Stimulating Hormone; $\mathrm{LH}=$ Luteinizing Hormone. 


\section{Global Relative Power}

The global relative power of the significant differences between the women with minimal and moderate depressive symptoms is shown in Figure 2. There were only significant differences between the groups for the alpha1 $(p=.01)$ and beta $2(p$ $=.03)$ bands. The delta $(p=.80)$, theta $(p=.73)$, alpha2 $(p$ $=.60)$, and betal $(p=.30)$ bands did not show significant differences between groups. Comparisons between groups showed that the relative power of alphalwas significantly lower in the group with minimal depressive symptoms and was highest in the groups with moderate depressive symptoms. The relative power of the beta2 band was significantly highest in the group with minimal depressive symptoms and was lower in the group with moderate depressive symptoms.

\section{Correlations between Hormones and EEG Relative Power}

The results of correlations between hormone levels and resting-state EEG relative power are shown in Table 4. In women with minimal depressive symptoms, estrone was negatively correlated with the relative power of alpha2 band $(\mathrm{r}=-.68, p$ $=.03$ ) and estradiol was positively correlated with the theta band $(\mathrm{r}=.68, p=.02)$ and negatively correlated with the beta2 band $(\mathrm{r}=-62, p=.05)$. In women with moderate depressive symptoms, progesterone was negatively correlated with the relative power of the theta band $(\mathrm{r}=-.80, p=.005)$ and positively correlated with the beta 2 band $(\mathrm{r}=.68, p=.02)$.

\section{Multiple Regression Analysis}

The results of the multiple regression analysis performed with both moderates and minimum depressive symptoms are shown in Table 5. The analysis showed that the relative power of the theta band, the alpha2 band, years of menopause and log estradiol were included in the regression model, accounting for $14.57 \%$ of the variance.

\section{Discussion}

The present findings confirmed the hypothesis that postmenopausal women showed different indices of depressive symptoms related to brain function measures and hormone levels, which were predictors of depression. Beck scores from

Table 4.

Correlation between EEG relative power bands and hormone levels in postmenopausal women with minimal and moderate depressive symptoms.

\begin{tabular}{|c|c|c|c|c|c|c|}
\hline \multirow{3}{*}{ Hormones } & \multicolumn{6}{|c|}{ Minimal Depressive Symptoms } \\
\hline & \multicolumn{6}{|c|}{ Spectral Bands } \\
\hline & Delta & Theta & Alpha1 & Alpha2 & Beta1 & Beta2 \\
\hline FSH (mUI/mL) & .31 & -.27 & -.15 & 0.31 & -.02 & .04 \\
\hline $\mathrm{LH}(\mathrm{mUi} / \mathrm{mL})$ & .33 & .21 & .05 & -.12 & -.43 & -.29 \\
\hline Progesterone (ng/mL) & .38 & .5 & .31 & .15 & -.59 & -.48 \\
\hline Estrone $(\mathrm{pg} / \mathrm{mL})$ & .01 & .57 & .33 & $-.68^{*}$ & -.46 & -.41 \\
\hline \multirow[t]{2}{*}{ Estradiol $(\mathrm{pg} / \mathrm{mL})$} & .22 & $.68^{*}$ & .55 & -.33 & -0.47 & $-.62^{*}$ \\
\hline & \multicolumn{6}{|c|}{ Moderate Depressive Symptoms } \\
\hline FSH $(\mathrm{mUI} / \mathrm{mL})$ & -.1 & -.13 & -.24 & -.52 & .34 & .22 \\
\hline $\mathrm{LH}(\mathrm{mUi} / \mathrm{mL})$ & .05 & -0.22 & -.52 & -.49 & .41 & .33 \\
\hline Progesterone (ng/mL) & .13 & $-.80^{* *}$ & -.52 & .01 & .53 & $.68^{*}$ \\
\hline Estrone $(\mathrm{pg} / \mathrm{mL})$ & -.06 & -.1 & -.29 & -.21 & -.08 & .16 \\
\hline Estradiol $(\mathrm{pg} / \mathrm{mL})$ & .79 & -.39 & -.44 & .14 & .14 & .46 \\
\hline
\end{tabular}

Note: ${ }^{*} p<.05,{ }^{* *} p<.01$ Spearman Correlation test.

Table 5.

Predictors of depressive symptoms in postmenopausal women.

\begin{tabular}{lccc}
\hline & \multicolumn{3}{c}{ Multiple Regression Model Adjusted } \\
\cline { 2 - 3 } Depressive symptoms & \multirow{2}{c}{$\mathrm{R}^{2}=.1457$} & \\
\cline { 2 - 3 } & $\beta$ & $\mathrm{t}$ & $.031^{*}$ \\
\hline Theta & -1.110 & -2.407 & $.029^{*}$ \\
Alpha2 & -.956 & -2.437 & $.029^{*}$ \\
Menopause (years) & .560 & 2.440 & $.032^{*}$ \\
Log. Estradiol (pg/ml) & -.811 & -2.378 & \\
\hline
\end{tabular}

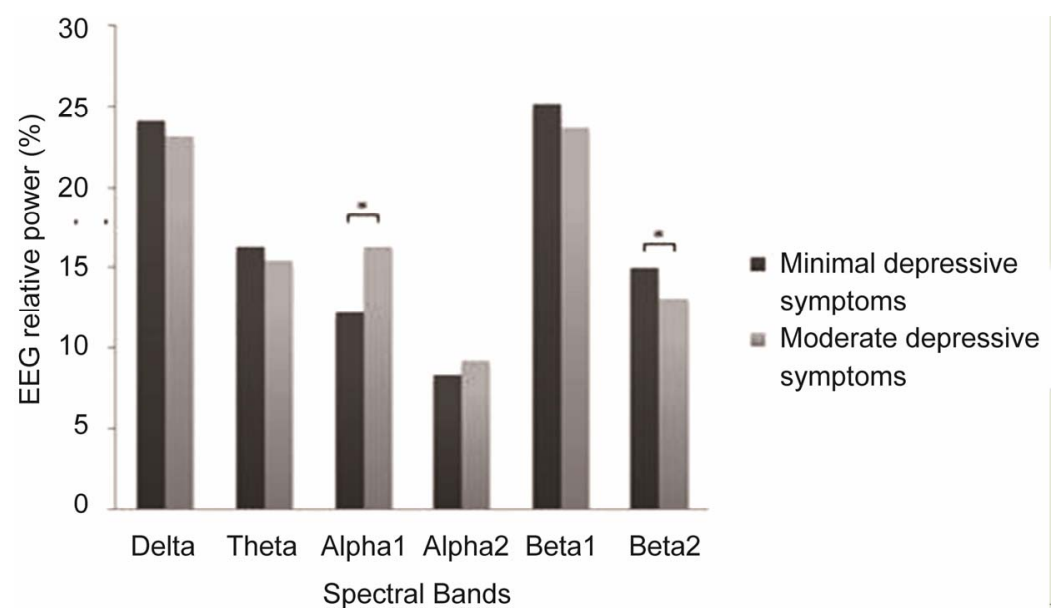

Figure 2.

Shows EEG relative power (\%) for delta, theta, alpha1, alpha2, beta and beta 2 bands between postmenopausal women with minimal and moderate depressive symptoms. Asterisks on the bars indicate significant differences between groups $\left({ }^{*} p<.05\right)$. 
the participants ranked as minimal to moderate depressive symptoms, and the significance between them was relevant. This result explained $73.10 \%$ of the total variance. The participants' characteristics were similar between the groups with minimal and moderate depressive symptoms. Menopausal years were confirmed as a significant predictor of depressive symptoms, explaining part of the variance in the multiple regression analysis. These results partially coincide with other studies that have investigated the relationship between menopause and psychological symptoms, especially depression. Epidemiological studies have found that the transition to menopause and its changing hormonal milieu is strongly associated with new onset of depressed mood among women with no history of depression (Freeman, Sammel, \& Nelson, 2006). A prospective study demonstrated that women with a history of depression are nearly five times more likely to have a diagnosis of major depression during the menopausal transition, whereas women with no history of depression are two to four times more likely to report depressed mood compared with premenopausal women (Freeman, 2010). It has also been reported that the risk of experiencing a major depressive episode is greater for women aged 42 - 52 years during the peri-menopausal or early postmenopausal periods than when they were pre-menopausal (Bromberger et al., 2011).

Depressive symptoms analyzed in the current study showed significant correlations between hormone levels of estrogen and progesterone and EEG relative power. Postmenopausal women with moderate depressive symptoms exhibited more relative alphal power (the slow component of the alpha band) and less relative beta2 power (fast activity) compared with the group with minimal depressive symptoms, suggesting decreased brain electrical activity. Several brain function studies have revealed important relations between depressive mood and EEG studies, supporting the current findings. Increased alpha or theta power has been observed in patients with major depression, mainly in the left anterior region of the brain, which has been called frontal alpha asymmetry (Monakhov \& Perris, 1980; Pollock \& Schneider, 1990; Alper, 1995; Debener et al., 2000; Allen \& Cohen, 2010) and has been interpreted as frontal hypoactivation (Henriques \& Davidson, 1991). Although the current study did not find significant differences in relative theta power, the multiple regression analysis showed that both theta and alpha relative power (slow activity) were significant predictors of depressive symptoms, explaining $14.57 \%$ of variance, and were negatively associated with Beck depression scores. An increase in slow (theta and alpha) activity and a diffuse enhancement of beta power were found in patients with early stages of depression at parietal and occipital sites, reflecting decreased cortical activation in these regions (Grin-Yatsenko, Baas, Ponomarev \& Kropotov, 2010). EEG maps of menopausal women with major depression also demonstrated less total power, less alpha power and more relative delta power, suggesting vigilance decrement (Saletu et al. 1996) and an augmentation of relative delta/theta and beta activity (Saletu, Anderer, \& Saletu-Zyhlarz, 2010). A study reported that depressed individuals exhibited higher baseline EEG theta activity within the region of the rostral anterior cingulated cortex, and this activity in the left precuneus was negatively correlated with changes in Beck depression scores (Pizzagalli et al., 2001). Clinical features of major depression disorder have been associated with decreased dorso prefrontal cortex and dorsal anterior cingulated gyrus activity (Brody, Barsom, Bota, \& Saxena, 2001). The beta 2 frequency band has been recorded in different conditions of increased alertness (Steriade, 1993) and has been correlated with poorer health status and age in depressed subjects (Morgan et al., 2005).

Furthermore, serum levels of progesterone were inversely correlated with slow activity (the theta band involved in emotional processes) and were positively correlated with fast activity (the beta 2 band involved in arousal) in the group of women with moderate depressive symptoms analyzed here. Accumulating evidence indicates that progesterone induces negative mood, most likely mediated via the action of progesterone metabolites binding to the $\mathrm{GABA}_{\mathrm{A}}$ receptor complex potentiating GABAergic inhibitory mechanisms and hence excitability (Majewska, Harrison, Schwartz, Barker, \& Paul, 1986; Rupprecht, Hauser, Trapp, \& Holsboer, 1996; Eser et al., 2006; Amin et al., 2006; Wang, 2011). Although serum progesterone levels are low in the postmenopausal period, the concentrations of progesterone and its metabolite, allopregnanolone, are high in the postmenopausal brain, particularly in amygdale (Bixo, Andersson, Winblad, Purdy, \& Bäckström, 1997), brain structure involved in mood. Allopregnanolone also has the ability to potentiate $\mathrm{GABA}_{\mathrm{A}}$-mediated inhibition of serotonergic neurons of the dorsal raphe nucleus (Robichaud \& Debonnel, 2006; Kaura, Ingram, Gartside, Young, \& Judge, 2007), which seems to have relevance for depressive mood.

In contrast, in the group of women with minimal depressive symptoms analyzed in the present study, serum levels of estradiol were also positively correlated with slow activity (relative theta power), whereas levels of estradiol and estrone were inversely correlated with fast activity (alpha 2 and beta2 bands). Furthermore, estradiol was confirmed to as a predictor of depression in the multiple correlation analysis, which was negatively associated with moderate depressive symptoms. These results suggest that serum levels of estrogens appear to influence the mechanisms that modulate emotional processes, indicated by theta activity involved in emotional regulation (Niedermeyer, 1993; Knyazev, 2007), favoring the manifestation of minimal depressive symptoms. At the same time, they maintain low arousal, indicated by the fast activity. This finding is consistent with other studies that have proposed that the marked decrease of estrogen at menopause and postmenopause could explain depressive symptoms because a decrease in estrogen results in decreased density of serotonin receptors and lower activity of serotonin (Joffe \& Cohen, 1998; Rybaczyk et al., 2005; Lasiuk \& Hegadoren, 2007) with hormonal effects on neurotransmitters and mood (Soares \& Zitek, 2008). Estradiol binds with a high affinity to both estrogen receptor (ER) isoforms, ER $\alpha$ and ER $\beta$, which are expressed in many regions of the brain in rats including the amygdale, brain region is known to be involved in the modulation of mood (Osterlund, Keller, \& Hurd, 2000; McEwen, 2001). Estrogen receptors and serotonin receptors coexist in cells in a wide variety of tissues, suggesting that many of the effects of estradiol receptors may be mediated by changes in the actions of serotonin (Rybaczyk et al., 2005). Therefore, it is plausible that these changes are related to mood and brain function in females with low circulating levels of estradiol in the postmenopausal period.

In conclusion, the current findings suggest that slow and fast EEG relative power, estradiol and menopausal years are predictors of depressive symptoms in postmenopausal women without a diagnosis of major depression. These findings also add information on role of progesterone on brain function for postmenopausal depressive symptoms and must be considered 
for hormone treatments.

There are some limitations that must be addressed in the present study. This study was conducted in a specific sample of postmenopausal women with low levels of estrogen and without major depression. The study did not include postmenopausal women with hormone replacement therapy and with a diagnosis of major depression, which must be included in future approaches. Another limitation of the study is that included a group of women between 48 and 65 years. Other studies must include individuals of different ages and gender. Prospective and longitudinal designs that include hormone replacement therapy with estrogen and progesterone in patients with depression and brain function analysis may contribute to improve understanding of depressive symptoms on cortical activity.

\section{Author Contributions}

SSO conceived, designed, and performed the study and data analysis and drafted the manuscript. EPL conducted the hormonal analyses. MPPZ performed the study and contributed to the data analysis. All authors have read and approved the final manuscript.

\section{Acknowledgements}

This work was supported by the University of Guanajuato. The authors wish to acknowledge the participation of Ma. Teresa Sepúlveda-Angulo in the recruitment of some participants. Ma. del Pilar Pacheco-Zavala received a CONACYT scholarship (184999) for work on her master's degree.

\section{REFERENCES}

Adler, G., Bramesfeld, A., \& Jajcevic, A. (1999). Mild cognitive impairment in old-age depression is associated with increased EEG slow-wave power. Neuropsychobiology 40, 218-222. doi: $10.1159 / 000026623$.

Allen, J. J., \& Cohen, M. X. (2010). Deconstructing the "resting" state: Exploring the temporal dynamics of frontal alpha asymmetry as an endophenotype for depression. Frontiers in Human Neuroscience 4, 232. doi:10.3389/fnhum.2010.00232

Alper, K. (1995). Quantitative EEG and evoked potentials in adult psychiatry. In J. Panksepp (Ed.), Advances on biological psychiatry (pp. 65-112). Greenwich, CT: JAI Press.

American Psychiatric Association (2000). Diagnostic and statistical manual of mental disorders text revision. Washington, DC: American Psychiatric Association.

Amin, Z., Mason, G. F., Cavus, I., Krystal, J. H., Rothman, D. L., \& Epperson, C. N. (2006). The interaction of neuroactive steroids and GABA in the development of neuropsychiatric disorders in women. Pharmacology, Biochemistry and Behavior 56, 635-638. doi:10.1016/j.pbb.2006.06.007

Beck, A. T., \& Steer, R. A. (1993). Beck depression inventory. San Antonio, TX: The Psychological Corporation.

Begić, D., Popović-Knapić, V., Grubišin, J., Kosanović-Rajačić, B., Filipčić, I., Telarović, I., \& Jakovljević, M. (2011). Quantitative electroencephalography in schizophrenia and depression. Psychiatria Danubina, 23, 355-362.

Birkhauser, M. (2002). Depression, menopause and estrogens: Is there a correlation? Maturitas, 41, S3-S8. doi:10.1016/S0378-5122(02)00009-9

Bixo, M., Andersson, A., Winblad, B., Purdy, R. H., \& Bäckström, T. (1997). Progesterone, 5alpha-pregnane-3,20-dione and 3alpha-hydroxy-5alpha-pregnane-20-one in specific regions of the human female brain in different endocrine states. Brain Research, 764, 173178. doi:10.1016/S0006-8993(97)00455-1
Brody, A. L., Barsom, M. W., Bota, R. G., \& Saxena, S. (2001). Prefrontal-subcortical and limbic circuit mediation of major depressive disorder. Seminars in Clinical Neuropsychiatry, 6, 102-112. doi:10.1053/scnp.2001.21837

Bromberger, J. T., \& Kravitz, H. M. (2011). Mood and menopause: Findings from the Study of Women's Health Across the Nation (SWAN) over 10 years. Obstetrics and Gynecology Clinics of North America, 38, 609-625. doi:10.1017/S003329171100016X

Bromberger, J. T., Kravitz, H. M., Chang, Y. F., Cyranowski, J. M., Brown, C., \& Matthews, K. A. (2011). Major depression during and after the menopausal transition: Study of Women's Health across the Nation (SWAN). Psychological Medicine, 41, 1879-1888. doi:10.1017/S003329171100016X

Debener, S., Beauducel, A., Nessler, D., Brocke, B., Heilemann, H., \& Kayser, J. (2000). Is resting anterior EEG alpha asymmetry a trait marker for depression? Findings for healthy adults and clinically depressed patients. Neuropsychobiology, 41, 31-37. doi: $10.1159 / 000026630$

Dennerstein, L., \& Soares, C. N. (2008). The unique challenges of managing depression in mid-life women. World Psychiatry, 7, 137142.

Deslandes, A. C., De Moraes, H., Pompeu, F. A., Ribeiro, P., Cagy, M., Capitão, C., \& Laks, J. (2008). Electroencephalographic frontal asymmetry and depressive symptoms in the elderly. Biological Psychology, 79, 317-322. doi:10.1016/j.biopsycho.2008.07.008

Eser, D., Schüle, C., Baghai, T. C., Romeo, E., Uzunov, D. P., \& Rupprecht, R. (2006). Neuroactive steroids and affective disorders. Pharmacology, Biochemistry and Behavior, 84, 656-666. doi:10.1016/j.pbb.2006.05.020

Fink, G., Sumner, B. E., Rosie, R., Grace, O., \& Quinn, J. P. (1996). Estrogen control of central neurotransmission: Effect on mood, mental state, and memory. Cellular and Molecular Neurobiology, 16, 325-344. doi:10.1007/BF02088099

Freeman, E. W. (2010). Associations of depression with the transition to menopause. Menopause, 17, 823-827. doi:10.1097/gme.0b013e3181db9f8b

Freeman, E. W., Sammel, M. D., Lin, H., \& Nelson, D. B. (2006). Associations of hormones and menopausal status with depressed mood in women with no history of depression. Archives of General Psychiatry, 63, 375-382. doi:10.1001/archpsyc.63.4.375

Freeman, E. W., Sammel, M. D., Liu, L., Gracia, C. R., Nelson, D. B., $\&$ Hollander, L. (2004). Hormones and menopausal status as predictors of depression in women in transition to menopause. Archives of General Psychiatry, 61, 62-70. doi:10.1001/archpsyc.61.1.62

Frey, B. N., Lord, C., \& Soares, C. N. (2008). Depression during menopausal transition. Menopause International, 14, 123-128. doi:10.1258/mi.2008.008019

Grin-Yatsenko, V. A., Baas, I., Ponomarev, V. A., \& Kropotov, J. D. (2010). Independent component approach to the analysis of EEG recordings at early stages of depressive disorders. Clinical Neurophysiology, 121, 281-289. doi:10.1016/j.clinph.2009.11.015

Harlow, B. L., \& Abraham, M. E. (1999). Depression in menopause. In D. B. Seifer, \& E. A. Kennard (Eds.), Menopause: Endocrinology and Management (pp. 111-124). U. S. A: Humana Press.

Henriques, J. B., \& Davidson, R. J. (1991). Left frontal hypoactivation in depression. Journal of Abnormal Psychology, 100, 535-545. doi:10.1037/0021-843X.100.4.535

Herrington, J. D., Heller, W., Mohanty, A., Engels, A. S., Banich, M. T., Webb, A. G., \& Miller, G. A. (2010). Localization of asymmetric brain function in emotion and depression. Psychophysiology, 47, 442-454. doi:10.1111/j.1469-8986.2009.00958.x

Joffe, H., \& Cohen, L. S. (1998). Estrogen, serotonin, and mood disturbance: Where is the therapeutic bridge? Biological Psychiatry, 44, 798-811. doi:10.1016/S0006-3223(98)00169-3

John, E. R., \& Prichep, L. S. (1993). Principles of neurometric analysis of EEG and evoked potentials. In E. Niedermeyer, \& F. H. Lopes Da Silva (Eds.), Electroencephalography Basic principles, clinical applications and related fields (pp. 989-1003). Baltimore, MD: Williams \& Wilkins.

Jurado, S., Villegas, M. E., Méndez, L., Rodríguez, F., Loperena, V., \& Varela, R. (1998). La estandarización del inventario de la depresión 
de Beck, para los residentes de la ciudad de México. Salud Mental, 21, 36-38.

Kaura, V., Ingram, C. D., Gartside, S. E., Young, A. H., \& Judge, S. J. (2007). The progesterone metabolite allopregnanolone potentiates GABA(A) receptor-mediated inhibition of 5-HT neuronal activity. European Neuropsychopharmacology, 17, 108-115. doi:10.1016/j.euroneuro.2006.02.006

Knyazev, G. G. (2007). Motivation, emotion, and their inhibitory control mirrored in brain oscillations. Neuroscience and Biobehavioral Reviews, 31, 377-395. doi:10.1016/i.neubiorev.2006.10.004

Kwon, J. S., Youn, T., \& Jung, H. Y. (1996). Right hemisphere abnormalities in major depression: Quantitative electroencephalographic findings before and after treatment. Journal of Affective Disorders, 40, 169-173. doi:10.1016/0165-0327(96)00057-2

Lasiuk, G. C., \& Hegadoren, K. M. (2007). The effects of estradiol on central serotonergic systems and its relationship to mood in women. Biological Research for Nursing, 9, 147-160. doi:10.1177/1099800407305600

Lebowitz, D. B., Pearson, J. L., \& Schneider, L. S. (1997). Diagnosis and treatment of depression in late life. Consensus Statement update. The Journal of the American Medical Association, 278, 1186-1190. doi:10.1001/jama.1997.03550140078045

Maartens, L. W., Knottnerus, J. A., \& Pop, V. J. (2002). Menopausal transition and increased depressive symptomatology: A community based prospective study. Maturitas, 42, 195-200. doi:10.1016/S0378-5122(02)00038-5

MacQueen, G., \& Chokka, P. (2004). Special issues in the management of depression in women. Canadian Journal of Psychiatry, 49, 27S$40 \mathrm{~S}$.

Majewska, M. D., Harrison, N. L., Schwartz, R. D., Barker, J. L., \& Paul, S. M. (1986). Steroid hormone metabolites are barbiturate-like modulators of the GABA receptor. Science, 232, 1004-1007. doi:10.1126/science. 2422758

McEwen, B. S. (2001). Invited review: Estrogens effects on the brain: multiple sites and molecular mechanisms. Journal of Applied Physiology, 91, 2785-2801.

Meldrum, D. R., Davidson, B. J., Tataryn, IV., \& Judd, H. L. (1981). Changes in circulating steroids with aging in postmenopausal women. Obstetric and Gynecology, 57, 624-628.

Monakhov, K., \& Perris, C. (1980). Neurophysiological correlates of depressive symptomatology. Neuropsychobiology, 6, 268-279. doi:10.1159/000117769

Morgan, M. L., Witte, E. A., Cook, I. A., Leuchter, A. F., Abrams, M., \& Siegman, B. (2005). Influence of age, gender, health status, and depression on quantitative EEG. Neuropsychobiology ,52, 71-76. doi: $10.1159 / 000086608$

Niedermeyer, E. (1993). The normal EEG of the waking adult. In E. Niedermeyer, \& F. Lopes Da Silva (Eds.), Electroencephalography. basic principles, clinical applications, and related fields (pp. 131152). Baltimore, MD: Williams \& Wilkins.

Osterlund, M. K., Keller, E., \& Hurd, Y. L. (2000). The human forebrain has discrete estrogen receptor alpha messenger RNA expression: High levels in the amygdaloid complex. Neuroscience, 95, 333 -342. doi:10.1016/S0306-4522(99)00443-1

Pizzagalli, D., Pascual-Marquí, R., Nitschke, J. B., Oakes, T. R., Larson, C. L., Abercrombie, \& Davidson, R. J. (2001). Anterior cingulated activity as a predictor of degree of treatment response in major depression: Evidence from brain electrical tomography analysis. The American Journal of Psychiatry 158, 405-415. doi:10.1176/appi.ajp.158.3.405

Pollock, V. E., \& Schneider, L. S. (1990). Quantitative, waking EEG research on depression. Biological Psychiatry, 27, 757-780.
doi:10.1016/0006-3223(90)90591-O

Robichaud, M., \& Debonnel, G. (2006). Allopregnanolone and ganaxolone increase the firing activity of dorsal raphe nucleus serotonergic neurons in female rats. The International Journal of Neuropsychopharmacolpgy, 9, 191-200. doi:10.1017/S146114570500595X

Rubinow, D. R., Schmidt, P. J., \& Roca, C. A. (1998). Estrogen-serotonin interactions: Implications for affective regulation. Biological Psychiatry, 44, 839-850. doi:10.1016/S0006-3223(98)00162-0

Rupprecht, R., Hauser, C. A., Trapp, T., \& Holsboer, F. (1996). Neurosteroids: Molecular mechanisms of action and psychopharmacological significance. The Journal of Steroid Biochemistry and Molecular Biology, 56, 163-168. doi:10.1016/0960-0760(95)00233-2

Ryan, J., Burger, H., Szoeke, C., Lehert, P., Ancelin, M. L., \& Dennerstein, L. (2009). A prospective study of the association between endogenous hormones and depressive symptoms in postmenopausal women. Menopause, 16, 509-517. doi:10.1097/gme.0b013e31818d635f

Rybaczyk, L. A., Bashaw, M. J., Pathak, D. R., Moody, S. M., Gilders, R. M., \& Holzschu, D. L. (2005). An overlooked connection: Serotonergic mediation of estrogen-related physiology and pathology. BMC Womens Health, 5, 12. doi:10.1186/1472-6874-5-12

Saletu, B. (1993). Neurophysiological and psychometric evaluation of central effects of classic and novel antidepressants. EEG mapping in depression. In J. Mendlewicz, N. Brunello, S. Z. Langer, \& G. Racagni (Eds.), New pharmacological approaches to the therapy of depressive disorders. International Academy for Biomedical and Drugs research (pp. 48-61). Basel, Paris, London, New York, Singapore, Tokyo, Sydney: Karger.

Saletu, B., Anderer, P., \& Saletu-Zyhlarz, G. M. (2010). EEG topography and tomography (LORETA) in diagnosis and pharmacotherapy of depression. Clinical EEG and Neuroscience, 41, 203-210. doi:10.1177/155005941004100407

Saletu, B., Brandstätter, N., Metka, M., Stamenkovic, M., Anderer, P., Semlitsch, H. V., \& Koll, B. (1996). Hormonal, syndromal and EEG mapping studies in menopausal syndrome patients with and without depression as compared with controls. Maturitas, 23, 91-105. doi:10.1016/0378-5122(95)00946-9

Smith, L. (1996). Causality, menopause and depression: A critical review of the literature. British Medical Journal, 313, 1229-1232. doi:10.1136/bmj.313.7067.1229

Soares, C. N. (2010). Can depression be a menopause-associated risk? BMC Medical Research Methodology, 8, 79.

Soares, C. N., \& Zitek, B. (2008). Reproductive hormone sensitivity and risk for depression across the female life cycle: A continuum of vulnerability? Journal of Psychiatry and Neuroscience, 33, 331-343.

Steriade, M. (1993). Cellular substrates of brain rhythms. In E. Niedermeyer, \& F. Lopes Da Silva (Eds.), Electroencephalography: Basic principles, clinical applications, and related fields (pp. 27-62). Baltimore, MD: Williams \& Wilkins.

Studd, J., \& Panay, N. (2004). Hormones and depression in women. Climacteric, 7, 338-346. doi:10.1080/13697130400012262

Vesco, K. K., Haney, E. M., Humphrey, L., Fu, R., \& Nelson, H. D. (2007). Influence of menopause on mood: A systematic review of cohort studies. Climacteric, 10, 448-465. doi: $10.1080 / 13697130701611267$

Wang, M. (2011). Neurosteroids and GABA-A receptor function. Frontiers in Endocrinology, 2, 44. doi:10.3389/fendo.2011.00044

Woods, N. F., Smith-DiJulio, K., Percival, D. B., Tao, E. Y., Mariella, A., \& Mitchell, S. (2008). Depressed mood during the menopausal transition and early postmenopause: Observations from the Seattle Midlife Women's Health Study. Menopause, 15, 223-232. doi:10.1097/gme.0b013e3181450fc2 